\title{
Erratum to: Research advances in expansins and expansin- like proteins involved in lignocellulose degradation
}

\author{
Xuewei Liu $\cdot$ Yuanyuan Ma $\cdot$ Minhua Zhang
}

Published online: 1 March 2016

(C) Springer Science+Business Media Dordrecht 2016

1 Erratum to: Biotechnol Lett (2015)

37:1541-1551

DOI 10.1007/s10529-015-1842-0

Unfortunately, in the original publication the word "expansin-like" had been typeset as "expansion-like" in article title. The correct title is provided in this erratum.
The online version of the original article can be found under doi:10.1007/s10529-015-1842-0.

X. Liu $\cdot$ Y. Ma $(\bowtie) \cdot$ M. Zhang R\&D Center for Petrochemical Technology, Tianjin University, Tianjin 300072, People's Republic of China e-mail: myy@tju.edu.cn

X. Liu

Department of Biochemical Engineering, School of Chemical Engineering and Technology, Tianjin University, Tianjin 300072, People's Republic of China

M. Zhang

Key Laboratory for Green Chemical Technology of Ministry of Education, R\&D Center for Petrochemical Technology, Tianjin University, Tianjin 300072,

People's Republic of China

M. Zhang

Collaborative Innovation Center of Chemical Science and Engineering, Tianjin 300072, People's Republic of China 